DOI: $10.17805 / z p u .2019 .3 .13$

\title{
Фразеологические единицы с кулинарным компонентом в симболарии карнавальной культуры Средневековья
}

\author{
Ю. П. ВЫШЕНСКАЯ \\ РОССИЙСКИЙ ГОСУДАРСТВЕННЫЙ ПЕДАГОГИЧЕСКИЙ УНИВЕРСИТЕТ \\ ИМ. А. И. ГЕРЦЕНА
}

Настоящее исследование выполнено в русле контрастивного направления и обращено к изучению вопроса об образности фразеологических единиц. Контрастивность характера исследования предполагает выявление и описание принципов отбора образных оснований фразеологизмов как косвенное свидетельство связи единиц данной природы с окультуренным мировосприятием того или иного народа. Предлагается опыт сравнительно-сопоставительного анализа функционирования означенного типа фразеологических единиц в произведениях карнавализованных жанров английской и француской литературы эпохи позднего Средневековья и раннего Возрождения. Это дает возможность сопоставить окультуренное мировосприятие в британской и романской модификациях.

Тип мировосприятия находит отображение в симболарии средневековой культуры, характеризуемом изменчивостью, обусловленной изменчивостью форм сознания в культурном сообществе на определенном этапе развития, и репрезентировано в создаваемых культурой текстах.

Культурная значимость фразеологических единиц в тексте-источнике значительно отличается культурной значимостью в синхронно рассматриваемом тексте, чем вызвано внимание к интерпретации направления смысловых изменений, которым подвергаются фразеологические единицы.

Важное положение в симболарии средневековой карнавальной культуры занимают фразеологические единицы с кулинарным компонентом. Эта группа формирует своеобразный кулинарный код как разновидность культурного кода, той призмы, сквозь которую раскрываются национальные особенности миропонимания.

Ключевые слова: карнавализованные литературные жанры; контрастивное направление; креативный потенциал; кулинарный код; мировоззреческая модель; пародия; фразеологическая единица; Средневековье

\section{ВВЕАЕНИЕ}

Ч астоящее исследование обращено к проблеме взаимосвязи этнического миро1 видения и путей его выражения в языке. Сфера исследуемого материала ограничивается фразеологией, представленной сегментом фразеологических единиц с кулинарным компонентом, фиксируемых в произведениях карнавализованных жанров. Обращение к произведениям английской и французской литературы периода смены Средневековья Возрождением придает исследованию сравнительный характер, что помогает выявить общие и отличные черты в процессах формирования культурного кода.

Рамки контрастивного направления содержат круг вопросов, связанных с избирательной образностью определенного народа, что находит отражение в национальной специфике при отборе образных оснований фразеологизмов.

Исследования контрастивного характера, число которых в последнее время неуклонно увеличивается, сосредоточены на анализе следов взаимодействия языка и культуры, чем обусловлено сочетание диахронического и синхронического подходов при изучении фразеологии в культурном контексте. Комбинация подобного рода 
предполагает не только сопоставление исходной значимости фразеологических единиц, фиксируемых в тексте-источнике, со значимостью сравниваемых с ними фразеологических единиц в синхронно рассматриваемом тексте, но также интерпретацию «“линии смысловых сдвигов” от исходной культурной значимости культурем, выделяемых в тексте-источнике» (Сорокин, 1994: 26; ср.: Duneton, 1985: 17).

Изменчивость культуры и контрастивность направления ее изучения тесным образом связаны с различиями в отборе образных оснований фразеологических единиц, что можно рассматривать как аргумент в пользу связи этой группы лексических единиц с окультуренным мировосприятием.

Связующим звеном мировосприятия и культуры является одна из ключевых ее составляющих, для обозначения которой В. Н. Телия вводит термин «симболарий», понимаемый как «флуктуирующий в пространственно-временном измерении набор ментальных структур, отображающий окультуренное миросознание и выработанные в нем установки жизненных практик, характерных для культурного сообщества (Телия, 1999: 21).

Характерную особенность симболария средневековой смеховой культуры представляет собой наличие внутри нее массива фразеологических единиц с кулинарным компонентом.

Посредством этой группы «образных метафорических переосмыслений исходных значений» формируется своеобразный культурный код, призма, сквозь которую раскрываются национальные особенности миропонимания (Аанилова В., Аанилова Г., 2014: 129).

Фразеологические единицы (ФЕ) с кулинарным компонентом можно рассматривать как разновидность пиршественных образов, тесно взаимосвязанных с образом тела, центрального в номенклатуре карнавальных образов в теории смеховой культуры Средневековья М. М. Бахтина.

Сферой их бытования в средневековой литературе являются карнавализованные жанры, которые обладают рядом сходных и отличительных характеристик в английской и французской литературе.

“КУАИНАРНЫЕ” ФРАЗЕОАОГИЗМЫ КАК РАЗНОВИАНОСТЬ

ПИРШЕСТВЕННЫХ ОБРАЗОВ СРЕАНЕВЕКОВОЙ КАРНАВААЬНОЙ КУАБТУРЫ

В недрах карнавальной смеховой модели, принадлежащей к спектру мировоззреческих моделей, возникающих в результате действия неравновесности средневековой европейской культуры (Можейко, 2000: 25; ср.: Soulnier, 1965: XXXIX, Doctor, 1994: 25), появляется импульс, который стимулирует формирование новых литературных карнавализованных жанров. Их образная система выстраивается в «незавершенном настоящем», зоне «фамильярного контакта автора и реципиента в плане пародирования традиционных, догматически серьезных жанров» (Амитриев, Сычев, 2005: 45).

Жанр фабльо, как пример карнавализованного жанра, представлен в английской литературе прологом к 'The Wyf of Bath's Tale' ( «Рассказ Батской Ткачихи») в поэме 'The Canterbury Tales' («Кентерберийские рассказы», 1995) Аж. Чосера.

Как отмечается в ряде исследований, текст поэмы изобилует разного рода ФЕ, пословицами и поговорками (Dragstra, 1991: 20). ФЕ, образные основания которых следует искать в кулинарной тематической плоскости, тесным образом связаны с пиршественными образами, важными в теории карнавального мировоззрения. 
Особое место в этой группе ФЕ занимают библеизмы, которые по помещении их в новый контекст подвергаются переосмыслению, наделяются функциями, не свойственными оригинальным, сообразно законам и образам гротескного реализма. Тем, как представляется, обусловлено наличие ФЕ гастрономического круга, реминисценций и аллюзий, в состав которых входит компонент "bread" (хлеб), порождающее ряд ассоциаций с библейскими притчами, получающими иное истолкование в контексте поэмы:

I nil anvye no virginitee;

Lat hem, be breed of pured whete-seed,

And lat us wyves hoten barly-breed;

And yet barly-breed, Mark telle can...1

(Chaucer, 1995: 294).

Цитируемый текстовый отрывок представляет собой фрагмент монолога Ткачихи, героини поэмы, интерпретируемый согласно традиции как полемика с авторитетными текстами, в данном случае - Священным Писанием.

Посредством метафорического образования breed of pured whete-seed подчеркивается особая ценность, придаваемая в христианской культуре дару непорочности. Согласно документальным данным, хлеб из пшеничной муки был в средневековой Англии, как и в континентальной части Европы, доступным кругу избранных деликатесом.

Появление антонимичного выражения boten barly-breed обусловлено самим полемическим характером анализируемого отрывка, в котором излагаются взгляды героини на самый институт брака, роль, отводимую в нем женщине, ее положение в современном ей социуме.

Стилистические приемы, представленные в данном текстовом фрагменте, не ограничиваются группой лексической природы, потому его можно рассматривать как стилистическое сгущение (Ажанджакова, 1983: 57).

Звенья цепи метонимико-метафорических приращений, получаемых словом bread, соединены полисиндетоном, ведущим принципом организации канонического текста, что возможно интерпретировать как своего рода синтаксический аналог аллюзии, и увенчиваются собственно неточной аллюзией на повествуемые в Библии чудесные деяния.

Немаловажная роль принадлежит также зафиксированным в тексте поэмы ФЕ с локальной этнической окраской:

The becoun was not for hem, I trowe, That som men han in Essex at Dunmowe ${ }^{2}$

(Chaucer, 1995: 296; курсив мой. -Ю. В.).

Упоминаемый в тексте Аенмауский окорок - пример ФЕ, значение которой интерпретируется как «награда супружеской чете, живущей в мире и согласии». Происхождение этого фразеологизма в соответствии с документальными свидетельствами обязано некогда существовавшему в Аенмау, графстве Эссекс, обычаю выдавать супругам, долгое время ладившим в браке, награду в виде окорока (Кашкин, 1988: 548). 
Отдельную группу образных выражений составляют выражения, в состав которых входят названия крепких напитков:

\author{
"Abyde!" quod she, my tale is not bigonne; \\ Nay, thou shalt drinken of another tonne \\ Er that I go, shal savoure wors than ale. \\ And whan that I have told thee borth my tale \\ Of triboulacion in marriage, \\ Of which I am expert in al myn age, \\ This to seyn, my-self, have been the whippe; - \\ Than maystow chese whether thou wolt sippe \\ Of thilke tonne that I shal abroche ${ }^{3}$
}

(Chaucer, 1995: 295).

Аанный фрагмент тематически связан с проанализированным выше - в нем представлен новый виток рассуждений героини о семейной жизни, предстающей в ином аспекте - полной присущих ей тягот. Тем обусловливается образное основание savoure wors than ale - горький вкус напитка. Впечатление о подстерегающих в браке сложностях усиливается путем контекстуальной корректировки.

Эта часть монолога героини завершается упоминанием еще одного напитка - wуn (вино), обязательного элемента застолья, который в античной культуре считался даром богов, неотъемлемым компонентом философских споров и дискуссий. Стол место не только увеселительных бесед, но также бесед другого содержания, что составляет двунаправленность образа, характерного одновременно для народной и христианской культуры: увеселение - наставление.

Now sires, now wol I telle forth my tale

As ever mote I drinken wyn or ale ${ }^{4}$

(Chaucer, 1995: 296).

Аналогичными примерами метафорического переосмысления изобилует текстовый материал произведения «Гаргантюа и Пантагрюэль» Ф. Рабле, послужившего своего рода фундаментом бахтинианской концепции карнавального мировоззрения.

Так, один из персонажей, участник «Беседы во хмелю», называемой М. М. Бахтиным «карнавальным симпосионом ${ }^{5}$ », произносит: «Je laverois volontiers les tripes de ce veau que j'ay ce matin habill?»6 (Бахтин, 2015: 292). Bыражение "babiller le veau»профессиональный термин со значением «разделывать тушу», сфера применения которого довольно узка и ограничивается речью мясников и текстами кулинарных книг. Вследствие встраивания в структуру художественного целого сфера применения этой ФЕ значительно расширяется, а вместе с этим получает расширение и набор «обертонов смысла», возникающих в результате метафорического переосмысления как «двойственности» отражаемой текстом реальной действительности согласно принципу à l'envers (обратности, колеса) - основного принципа карнавального мировосприятия. Анализируемая ФЕ, сохраняя исходное оригинальное терминологическое значение, демонстрирует двунаправленность, будучи использованной как для обозначения самого персонажа, одевшегося утром без посторонней помощи, так и теленка, которого перед тем освежевали и выпотрошили (там же). 
В приведенном примере наличествует выражение «laver les tripes» (промыть утробу, внутренности), также интерпретируемое сквозь призму кулинарного кода. Номинативный компонент «les tripes» (требуха, внутренности, утроба), входит в состав многочисленных французских ФЕ. Такова, например, ФЕ sac à tripes с просторечным значением «брюхо» (Французско-русский ..., 1963: 948), наиболее близкая к образу гротескного тела.

Переосмысление этого выражения в качественно новом контексте также происходит в результате действия принципа колеса. Сообразно «двойственности» отображаемого мира это выражение выступает обозначением утробы персонажа, которую он намеревается омыть вином, и одновременно утробы теленка, которую он намеревается запить вином.

Проанализированный случай использования выражения «laver les tripes» не является единственным и встречается в другом контекстном окружении произведений цикла «Гаргантюа и Пантагрюэль»:

«Voulez vous rien mandez à la rivière? Cestuy су (стакан с вином) vas laver les tripes» (Не надо ли вам передать что-либо на реку, он (стакан) идет мыть потроха) (Бахтин, 2015: 213; перевод М. Бахтина. - Ю. В.).

В приведенной цитате выражение les tripes оборачивается еще одним аспектом своего значения: «насытившаяся утроба» и «насытившая утроба».

По внимательном прочтении в этом примере можно увидеть также аллюзию на самый контекст его появления, который имеет непосредственное отношение к кулинарным пристрастиям простых людей, носителей и выразителей карнавального мировоззрения.

Изначально слово les tripes выступало как название блюда: тщательным образом промытые, посоленные и тушеные согласно рецептуре внутренности животного. В силу того что впрок это кушанье заготавливать было невозможно, то в дни убоя скота требуху поедали, не соблюдая меры, и продавали по символической цене (Бахтин, 2015: 213).

Следует отметить, что образ утробы, неразрывно связанный с образом тела, неоднократно фигурирует и в других образцах литературы гротескного реализма, в частности в виде латинского аналога «viscera».

Образ омываемой вином утробы положен в основу бытовавшего в эпоху Ф. Рабле обычая сопровождать выпитый стакан вина словами из покаянного псалма, завершающегося словами: «обнови меня в утробе моей» (in visceribus meis).

Задаваясь вопросом о важности роли, отводимой образу утробы в гротескном реализме, М. М. Бахтин вытраивает следующую аргументационную цепочку: внутренности отождествляются с чревом, утробой, что, в свою очередь, тождественно самой человеческой жизни (там же).

В том видится связь с проанализированным ранее образом ячменного хлеба, отождествляемого с жизнью, зарождающейся в женском чреве, в конечном итоге с жизнью.

Высокая значимость ФЕ рассматриваемого круга обретают в произведениях блазона (blazon), другой разновидности перечня карнавализованных жанров, характерных для анализируемой эпохи. В самом термине также находит отражение ее отмеченная двойственность, что проявляется не только в узкой геральдической специфике, но также в использовании для выражения одновременно хвалы и брани. Это значение возникает уже в старофранцузский период развития языка и сохраняется 
в эпоху Ф. Рабле с заметно стершимся отрицательным компонентом, по прошествии времени совершенно утрачиваемым, что сужает значение термина до только лишь хвалы (там же: 552).

Полагают, что эта разновидность карнавализованного жанра зарождается в народно-речевой стихии, источнике стилистических средств для представителей прогрессивной литературы эпохи. Проявление этой стихии - в двойственности оценки, «противоречивой полноте тона», иными словами, хвалы, обретает ироническое звучание и двусмысленный характер. Тем обусловлена возможность хвалить то, что по шкале истинных ценностей похвале не подлежит. Самый жанр блазона, вынесенный за рамки официальной системы оценивания, образуется синтезом хвалы и брани (там же: 553).

Сущность процесса генерирования блазона как карнавализованного жанра заключается в закреплении в большей или меньшей степени развернутых эпитетов амбивалентного характера с превалированием хулительного элемента. В силу стабильности характера такого рода эпитеты можно считать частью фонда пословиц и поговорок. Некоторые из них возникли как результат существовавшей народной традиции блазонизировать другие национальности, различные провинции, города, села.

Объектом блазонизации становятся те или иные пристрастия в области кулинарии, гастрономические предпочтения и привычки отдельных национальностей, что дает основание для выделения им отдельного сегмента в пиршественно-образном пространстве.

Примером блазонизации можно считать приписываемую англичанам французами неумеренность в употреблении крепких напитков, закрепленную в блазоне «Sauol comme un Anglais» (пьяный, как англичанин), характеризуемом устойчивостью, фиксируемом в произведениях Ф. Рабле. Согласно документальным свидетельствам, именно эта черта становится доминирующей в характеристике подданных английского королевства в восприятии подданных французской короны, что подтверждается выражением «Li mieldre buveor in Engleterre», зафиксированным в древнейшем сборнике XIII в. В основе этимологии этого выражения просматривается связь с подразумеваемой причиной, лексическими единицами wyn и ale, анализируемыми выше.

\section{ЗАКАЮЧЕНИЕ}

Проделанный анализ позволяет прийти к заключению, что ФЕ с кулинарным компонентом, образуя важную часть симболария карнавальной средневековой культуры, несут на себе отпечаток свойственной ей двойственности. Зарождаясь в ее недрах, ФЕ как в английском, так и французском языке формируются сообразно основополагающему принципу колеса, что определяет их амбивалентный характер. В силу древности происхождения ФЕ этого симболарного сегмента объединяются общностью составляющих их компонентов, обозначающих основные продукты из рациона человека.

В английском языке, как показывает анализ, велик удельный вес ФЕ с кулинарным компонентом bread, что порождает ассоциативный ряд с библейскими притчами, которые получают принципиально новое, пародийное переосмысление в художественном целом, в то время как во французской художественной прозе примеры такого рода отсутствуют. Точкой пересечения британского и романского мировосприятия является группа ФЕ с компонентом wyn. В дальнейшем ФЕ с кулинарным компонен- 
том подвергаются не только этнической переоценке, но, будучи частью фразеологического фонда, выступают источником стилистических исканий прогрессивных деятелей литературы своего времени. Попадая в структуру художественного текста, ФЕ с кулинарным компонентом претерпевают последующее переосмысление и получают приращения значения, согласно законам карнавализованных жанров, также являющихся порождением карнавальной смеховой культуры Средневековья.

\section{ПРИМЕЧАНИЯ}

1 Я не желаю девственность хулить, / С пшеничным хлебом деву я сравнить / Хотела бы, а жен с ячменным хлебом. Но и ячмень растет под тем же небом. / Апостол Марк в Евангелье вещал (Чосер, 1988: 284; пер. И. Кашкина).

2 Аэнмауский окорок не им был сужен (там же: 285 ).

3 Постой-ка, мой рассказ еще не начат. / Его услышав, запоешь иначе. / В той бочке погорчее будет эль, / Чем все, что рассказала я досель. / Ох, знаю я, едва ль кто лучше знает / Каким бичом супружество взимает / Свои налоги, - я сама тот бич. / И посоветуйся, / потом решайся / Пригубить рог. И уж затем не кайся, / Что эль супружества не больно сладок; / Примеры приведу я, как он гадок (там же: 284).

4 Так пусть бы приключилась / Со мной напасть, пусть эля и вина / Не пить мне больше, если не сполна (там же: 284).

5 Ритуализированным пиршеством, сопровождавшимся буйным весельем.

6 «Я охотно промою утробу этого теленка, которого одевал утром» (перевод наш. - Ю. В.).

\section{СПИСОК АИТЕРАТУРЫ}

Бахтин, М. М. (2015) Творчество Франсуа Рабле и народная культура средневековья и Ренессанса. М. : Искусство. 525 с.

Аанилова, В. А., Аанилова, Г. И. (2014) Фразеологизмы с кулинарным компонентом в контексте гастрономического кода немецкой национальной культуры // Studia Linguistica - XXIII. Язык и человек в фокусе современной науки / отв. ред. И. А. Щирова. СПб. : Политехника-сервис. 322 с. С. $128-137$.

Ажанджакова, Н. И. (1983) Анализ художественного прозаического текста. М. : МГПИИЯ им. М. Тореза. 72 с.

Амитриев, А. В., Сычев, А. А. (2005) Смех: социофилософский анализ. М. : Альфа. 592 с.

Кашкин, И. (1988) Примечания // Кентерберийские рассказы / пер. с англ. И. Кашкина и О. Румера. М. : Правда. 560 с. С. 528-558.

Можейко, М. А. (2000) Становление концепции нелинейных динамик в современной культуре (сравнительный анализ синергетических и постмодернистских исследовательских стратегий) : автореф. дис. ... А-ра филос. наук. Минск. 42 с.

Сорокин, Ю. А. (1994) Этническая конфликтология. Самара : Русский лицей. 96 с.

Телия, В. Н. (1999) Первоочередные задачи и методологические приемы исследования фразеологического состава в контексте культуры // Фразеология в контексте культуры / отв. ред. В. Н. Телия. М. : Языки русской культуры. 333 с. С. 13-25.

Французско-русский фразеологический словарь (1963) / под ред. Я. И. Рецкера М. : Гос. изд-во иностр. и нац. словарей. 1112 с.

Чосер, Аж. (1988) Кентерберийские рассказы / пер. с англ. И. Кашкина и О. Румера. М. : Правда. 560 с.

Chaucer, G. (1995) The Canterbury Tales. London : Wordsworth Editions Ltd. 632 p.

Doctor, J. A. (1994) Shakespeares carnival. Århus : Aarhus Universitetsforlag. 462 p.

Dragstra, H. (1991) Methods in twentieth-century Chaucer studies: an inquiry into cultural practice, 1915-1980. Rijksuniversiteit Groningen. 393 p.

Duneton, C. (1985) La Puce à l'Oreille. Mayenne : Ballard. 501 p. 
Soulnier, V. L. (1965) Introduction // Pantagruel/ Ed. by V. L. Soulnier. Genève : Librairie Droz. 265 p. P. VIII-L.

Aата поступления: 22.06.2018 2.

\section{PHRASEOLOGICAL UNITS WITH CULINARY COMPONENT IN THE SYMBOLARIUM \\ OF THE MEDIEVAL CARNIVAL CULTURE \\ YU. P. VYSHENSKAYA \\ HeRzen State PeDAGogICAL UNIVERSITY of RUSSia}

The study is conducted within the framework of the contrastive approach and deals with the issue of the imagery of phraseological units. The contrastive nature of the research implies identification and description of selection principles of descriptive phraseological bases as indirect evidence of the link between units of this nature and culture worldview of a nation. The author proposes a comparison-and-collation analysis of the functioning of the above mentioned types phraseological units in the works of carnivalised literary genres of English and French literature in the late Middle Ages and early Renaissance. This enables the author to compare and contrast culture worldview in British and Roman variations.

The worldview type is reflected in the medieval culture symbolarium characterized by variability, which is stipulated by the changeability of the forms of cognition in a culture society at a certain stage of its development, and represented in texts generated by culture.

The cultural significance of phraseological units in the source text has a far greater cultural relevance in the synchronically considered text. This triggers attention to the interpretation of the course of semantic changes which phraseological units are exposed to.

Phraseological units with a culinary component play an important role in the symbolarium of medieval carnival culture. This group forms a peculiar culinary code as a type of culture code; a prism which reveals national features of world cognition.

Keywords: carnivalised literary genres; contrastive direction; creative potential; culinary code; world-view pattern; parody; phraseological unit; Middle Ages

\section{REFERENCES}

Bakhtin, M. M. (2015) Tvorchestvo Fransua Rable i narodnaia kul'tura srednevekov'ia i Renessansa. Moscow, Iskusstvo. 525 p. (In Russ.).

Danilova, V. A., Danilova, G. I. (2014) Frazeologizmy s kulinarnym komponentom v kontekste gastronomicheskogo koda nemetskoi natsional'noi kul'tury. In: Studia Linguistica - XXIII. Iazyk $i$ chelovek $v$ fokuse sovremennoi nauki / ed. by I. A. Shchirov. St. Petersburg, Politekhnika-servis. 322 p. Pp. 128-137. (In Russ.).

Dzhandzhakova, N. I. (1983) Analiz kbudozhestvennogo prozaicheskogo teksta. Moscow, MGPIIIa im. M. Toreza. 72 p. (In Russ.).

Dmitriev, A. V. and Sychev, A. A. (2005) Smekb: sotsiofilosofskii analiz. Moscow, Al'fa. 592 p. (In Russ.).

Kashkin, I. (1988) Primechaniia. In: Kenterberiiskie rasskazy / transl. from Engl. by I. Kashkin and O. Rumera. Moscow, Pravda. 560 p. Pp. 528-558. (In Russ.).

Mozheiko, M. A. (2000) Stanovlenie kontseptsii nelineinykh dinamik v sovremennoi kul'ture (sravnitel' nyi analiz sinergeticheskikb i postmodernistskikb issledovatel'skikb strategii) : Thesis of Diss. ... Doctor of Philosophy. Minsk. 42 p. (In Russ.).

Sorokin, Iu. A. (1994) Etnicheskaia konfliktologiia. Samara, Russkii litsei. 96 p. (In Russ.).

Teliia, V. N. (1999) Pervoocherednye zadachi i metodologicheskie priemy issledovaniia frazeologicheskogo sostava v kontekste kul'tury. In: Frazeologiia v kontekste kul'tury/ ed. by V. N. Teliia. Moscow, Iazyki russkoi kul'tury. 333 p. Pp. 13-25. (In Russ.).

Frantsuzsko-russkii frazeologicheskii slovar' (1963) / ed. by Ia. I. Retsker. Moscow, Gos. izd-vo inostr. i nats. slovarei. 1112 p. (In Russ.). 
Choser, Dzh. (1988) Kenterberiiskie rasskazy / transl. from Engl. by I. Kashkin and O. Rumer. Moscow, Pravda. 560 p. (In Russ.).

Chaucer, G. (1995) The Canterbury Tales. London, Wordsworth Editions Ltd. 632 p.

Doctor, J. A. (1994) Shakespeares carnival. Århus, Aarhus Universitetsforlag. 462 p.

Dragstra, H. (1991) Methods in twentietb-century Chaucer studies: an inquiry into cultural practice, 1915-1980. Rijksuniversiteit Groningen. 393 p.

Duneton, C. (1985) La Puce à l'Oreille. Mayenne, Ballard. 501 p.

Soulnier, V. L. (1965) Introduction. In: Pantagruel / Ed. by V. L. Soulnier. Genève : Librairie Droz. 265 p. Pp. VIII-L.

Submission date: 22.06.2018.

Вышенская Юлия Павловна - кандидат филологических наук, доцент, доцент кафедры английского языка и лингвострановедения Российского государственного педагогического университета им. А. И. Герцена. Адрес: 191186, Россия, г. Санкт-Петербург, наб. реки Мойки, 48, к. 14. Тел.: +7 (812) 571-49-83. Эл. аapec: clemence_isaure@rambler.ru

Vyshenskaya Yuliya Pavlovna, Candidate of Philology, Associate Professor, Associate Professor, Department of English Language and British Studies, Herzen State Pedagogical University of Russia. Postal address: 48, Bldg. 14, Moyka Embankment, St. Petersburg, Russian Federation, 191186. Tel.: +7 (812) 571-49-83. E-mail: clemence_isaure@rambler.ru 